\title{
As Raízes Hinduístas do Budismo ${ }^{1}$
}

\author{
The Hindu Roots of Buddhism
}

Dilip Loundo

RESUMO

Pretendemos, com o presente artigo, evidenciar a inserção civilizacional eminentemente hinduísta da tradição do budismo, cujo contexto originário possui um caráter eminentemente iniciático. A inserção orgânica do budismo no contexto das religiosidades hindus (védicas/purânicas/tântricas) do subcontinente indiano, tanto em suas dimensões populares quanto naquelas de aprofundamento reflexivo, caracteriza, peculiarmente, a tradição do Mahāyāna e fornece os elementos epistemológicos fundamentais para a compreensão dos processos análogos que acompanharam a assimilação da palavra do Buda em territórios e civilizações distintos como é o caso do Tibet, da China e do Japão.

PALAVRAS-CHAVE: Budismo; Mahāyāna; Hinduísmo; Religião; Filosofia.

ABSTRACT

The objective of this article is to show that Buddhism is, originally, part of a larger Hindu civilizational context, and that its original configurations are marked by an eminent initiatory character. The organic insertion of Buddhism in the context of the Hindu (Vedic/Puranic/Tantric) religions of the Indian subcontinent, both in its popular and philosophical aspects, peculiarly characterizes the Mahāyāna tradition and provides one with fundamental epistemological tools to understand analogous dynamics that took place in the process of assimilation of the Buddha's words into other civilizations and territories, such as Tibet, China, and Japan.

KEYWORDS: Buddhism; Mahāyāna; Hinduism; Religion; Philosophy.

\footnotetext{
' Recebido em 30/05/2017. Aprovado em 30/09/2017. A transliteração das palavras em sânscrito e páli citadas neste artigo segue o IAST (International Alphabet of Sanskrit Transliteration). Por outro lado, as traduções de originais em sânscrito e páli incluídas neste artigo foram realizadas pelo autor. ${ }^{2}$ Doutor em Filosofia Indiana. Professor do Departamento de Ciência da Religião da Universidade Federal de Juiz de Fora.
} 


\section{I - Introdução}

Trabalhar com matrizes civilizatórias orientais e, principalmente, com matrizes que possuem um largo histórico de autorreflexão sobre as diferentes esferas da existência humana, como é o caso da Índia, torna inevitável uma certa angústia metodológica. A necessidade imperiosa de veicular as expressões mais vitais dessa existencialidade em termos dos conceitos modernos ocidentais de "religião" e "filosofia" exige um esforço preliminar criterioso de contextualização, adequação e qualificação de sentido, para que se evite macular projetos e produzir julgamentos ao invés de entendimentos.

Negligenciar essa tarefa preliminar abre as comportas para uma imposição subalternizante, redutora e reificadora desses conceitos e sua utilização meramente negativa ou metafórica. Com efeito, são muitos os casos em que a expressão "filosofia oriental" nada tem a ver com projetos de racionalidade e rigor lógico: ela constitui, ao invés, uma expressão contundente de rejeição das religiões ocidentais e, mais especificamente, o cristianismo - por sua exacerbação dogmatista e consequente ineficácia soteriológica. Similarmente, são muitos os casos em que a expressão "religião oriental" nada tem a ver com disciplinas de submissão da vontade e autotransformação: ela constitui, ao invés, uma expressão contundente de rejeição das filosofias ocidentais por seu caráter puramente especulativo ou teórico, sem qualquer repercussão na pragmaticidade da existência.

A postulação da imperiosidade dos esforços de contextualização, adequação e qualificação de sentido funda-se numa convicção epistemológica de que é possível uma dialogia e uma interatividade genuínas entre experiências civilizacionalmente diversas e plurais da existencialidade sofredora. Nesse sentido, ao invés de impositividades redutoras, os esforços de contextualização podem promover um processo salutar de recuperação de sentidos eventualmente adormecidosna tradição receptora. No que tange especificamente às palavras "religião" e "filosofia", os estudos das tradições orientais podem redundar num caminho insuspeito de revitalização de sentidos outrora dominantes em contextos antigos e clássicos gregos-romanos, muito além das reificações modernas da primeira ("religião") enquanto soteriologia (cristã) atrelada à imprevisibilidade de uma Graça absolutamente transcendente e da segunda ("filosofia") enquanto racionalidade árida e existencialmente neutra. Com isso, a traducibilidade que condiciona os diálogos inter-religiosos contemporâneos deixaria de constituir uma mera troca de informações sobre crenças cristalizadas para se investir do caráter de fator instigador da transformação dos interlocutores. 


\section{II - Budismo, Hinduísmo e o Modelo Religioso Bidimensional}

A investigação moderna do que consagramos, na área de ciência da religião, como duas das maiores religiosidades do mundo - o hinduísmo e o budismo - tem mostrado a indispensabilidade do recurso simultâneo, revitalizado e orgânico, aos dois conceitos acima referidos de "religião" e "filosofia". No que tange ao primeiro, o elemento de revitalização responde pela necessidade de se retomar a ideia de religião como fenômeno constitutivo e identificador de comunidades, i.e., como fonte simbólica de uma autoridade metaindividual que visa à transformação dos entes, aqui e agora, ao invés de uma comodidade, entre muitas outras, à disposição das escolhas racionais de subjetividades autárquicas. E no que tange ao segundo, o elemento de revitalização responde pela necessidade de se pensar a filosofia como razão e lógica instrumentais que, muito além de uma conclusividade teórica ou doutrinária, conduz, de forma imediata, a uma transformação espiritual dos entes, num contexto cognitivo onde ser e pensar se reconciliam.

Finalmente, o elemento de organicidade que vincula ambas asesferas revitalizadas da "religião" e da "filosofia" contém o mistério da realização do compromisso último que caracteriza, no hinduísmo e no budismo, a essencialidade espiritual, i.e., a soteriologia enquanto caminho de superação do sofrimento. Com efeito, em comum com a maioria das religiões mundiais, com exceção óbvia do cristianismo moderno, hinduísmo e budismo desenvolvem suas teleologias espirituais segundo dois vetores de progressão de sentido que correspondem, grosso modo, às esferas revitalizadas da "religião" e da "filosofia". A organicidade que se institui entre elas consagraria, então, a filosofia como dimensão intrínseca de aprofundamento da religião, visando à realização definitiva de uma condição de bem-aventurança e de conhecimento da natureza última do Real e do si-mesmo. São os seguintes os dois vetores de progressão de sentido nas tradições do hinduísmo e do budismo:

(i) O primeiro vetor ou nível introdutório (Nível 1) possui um caráter geral, popular ou comunitário e envolve, primordialmente, o cumprimento de preceitos morais, rituais e litúrgicos e a familiarização com narrativas míticas e princípios doutrinários e dogmáticos. Nele se alcança um desapego e um conhecimento parciais, geralmente conducentes, no contexto da doutrina da transmigração da alma [samsāra], a um renascimento paradisíaco, entendido como disfrute de uma condição aprimorada de bem-aventurança. Trata-se, entretanto, de uma condição inevitavelmente temporária, pois nela impera o princípio da dualidade e do intercurso sujeito-objeto. Os termos mais comumente usados para designar este nível introdutório são dharma (hinduísmo) ou samsāra (budismo).

(ii) O segundo vetor ou nível de aprofundamento (Nível 2) possui um caráter iniciático e envolve, primordialmente, a prática da razão meditativa, de caráter analítico, sobre a natureza última do sujeito e da realidade que o cerca. Nele se alcança o descentramento total do ego, 
expresso numa condição de desapego absoluto e de conhecimento pleno do Real. Este último - viz., o conhecimento pleno do Real consagra-se como superação da dualidade e como reconhecimento concomitante da natureza sempre-presente do Real enquanto unicidade (advaita) ou interdependência (pratityasamutpāda) ontológica entre sujeito e objeto, i.e., enquanto comunhão originária entre ambos. Os termos mais comumente usados para designar este nível último são mokṣa (hinduísmo) e nirvāṇa (budismo).54

Se no primeiro nível prepondera a ação interessada enquanto dimensão moral da religião, no segundo prepondera a razão analítica enquanto dimensão filosóficada mesma, que é conducente a uma condição de estar-no-mundo liberta definitivamente das intencionalidades egóicas. Ao invés de uma substituição, a progressão de um nível para o outro corresponde, necessariamente, a um alargamento de horizontes. Em outras palavras, o processo de progressão de sentido constitui-se num percurso de sequencialidades orgânicas e hierárquicas, no qual o primeiro nível constitui a plataforma de realização dos requisitos necessários para a imersão no segundo. 0 caráter iniciático deste último envolve, finalmente, a familiarização com literaturas, estruturas pedagógicas e disciplinas distintas e específicas.

Decorre, do acima exposto, que a dinâmica de transformação e seus desdobramentos iniciatórios, característica das religiosidades hindus e budistas, consubstancia-se, necessariamente, em processos sempre recorrentes de uma dialética existencial. Em outras palavras, longe da postulação cristã de uma "evolução" histórica do Velho para o Novo Testamento, as espiritualidades hindus e budistas sustentam que, em cada nascimento, se reedita a problemática existencial do sofrimento e dos caminhos para sua superação.

No que tange ao hinduísmo, o modelo bidimensional acima descrito - a religiosidade moral-ritual (Nível 1) e a religiosidade racional-meditativa (Nível 2) atravessa, categorialmente, a pluralidade de tradições religiosas que o constituem, e cuja consolidação contemporânea nas vertentes Vaișṇava, Śaiva, Śakta e Smārta, envolve o diálogo continuado entre diversas matrizes fundacionais, de caráter oral e escrito. Dentre essas matrizes, destacam-se, fundamentalmente, os Vedas, os Tantrase os Purāṇas e, suplementarmente, alguns legados de origem islâmica e cristã. Em que pesem os arroubos orientalistas de reificação dos Vedas enquanto fantasia emblemática de um arianismo de fundo racista (BRYANT, 2003, p. 13-45), o sentido contemporâneo da expressão "tradições védicas", frequentemente designativa do hinduísmo como um todo, pressupõe metonimicamente a complexidade dos encontros ocorridos entre as diversas matrizes acima referidas. Nesse sentido, o hinduísmo compreenderia, de fato, uma pluralidade de tradições védico-tântricopurânicas. É de notar, finalmente, quea palavra "hinduísmo", sugestiva de uma uniformidade inexistente, é, em suas origens, totalmente extrínseca à civilização do subcontinente indiano e sem maiores repercussões nas línguas vernáculas da região.

No que tange ao budismo, o modelo bidimensional supracitado pode-nos ajudar, de forma decisiva, a compreender, por um lado, a pluralidade de sentidos que 
a aparente homogeneidade da palavra oculta e, por outro, a articulação íntima que manteve, em suas origens, com a pluralidade das tradições védicas que ora designamos sob a palavra "hinduísmo". É esta última tarefa que me proponho empreender, de forma sucinta, nos parágrafos seguintes. Tal tarefa envolve, necessariamente, a desconstrução de algumas das "verdades" correntes no ocidente sobre o budismo indiano, a raiz fundadora dos budismos pelo mundo afora. Noto, também, que ao contrário da exterioridade originária da palavra "hinduísmo" com relação às "tradições védicas" e outras, a palavra "budismo" possui, sim, um elemento positivo de interioridade de sentido: purgado, se possível, das conotações ideológicas do sufixo "ismo", a palavra "budismo" poderia contemplar o sentido amplo de "ensinamentos do Buda" (bauddha). Noto, finalmente, que levarei em consideração muito especial nesta reflexão, as observações dos indólogos britânicos Richard Gombrich e Alexis Sanderson.

\section{III - A Inserção Civilizacional Hinduísta do Budismo Indiano}

Considerando o modelo bidimensional supracitado, o budismo na Índia não pode nem deve ser classificado como religião independente mas, ao invés,como uma dimensão de Nível 2 das religiosidades hindus.(GOMBRICH, 1971, p. 51-73) Em outras palavras, o budismo surge, no subcontinente indiano, como uma escola iniciática de aprofundamento filosófico no contexto das pluralidades védico-tântrico-purânicas que constituem o hinduísmo: uma escola entre muitas outras que o precederam, que Ihe foram contemporâneas, e que o sucederam. Surge como uma congregação de neófitos (sangha] que preenchem, por princípio, requisitos rigorosos de caráter ético e intelectuale cujo objetivo é empreender o estágio último de exercício da razão meditativa conducente à realização do Real e dos ideais do arhat e do bodhisattva. É interessante notar que a ênfase ocidental moderna no caráter "filosófico" do budismo parece reter essa dimensão fundamentalmente reflexiva e analítica. Entretanto, a desconsideração "populista" pelo cumprimento dos requisitos iniciáticos - viz., a plena vivência dos conteúdos de Nível 1 - e a consequente inaptidão para o correto exercício da reflexão analítica tendem a converter o budismo "ocidental" numa filosofia meramente teórica ou doutrinária e, portanto, existencialmente ineficaz.

Enquanto dimensão de aprofundamento filosófico (Nível 2), o budismo indiano está, portanto, organicamente integrado aos contextos das religiosidades morais e rituais (Nível 1) das tradições hindus. Nesse sentido, e sem desmerecer o fato de que os processos de transição entre níveis, envolvendo mudanças substantivas nas estruturas, pedagogias e literaturas de encaminhamento, são sempre acompanhados de situações de tensão e conflito, a ênfase das narrativas orientalistas modernas numa suposta rejeição radical, por parte do Buda histórico, das tradições e das literaturas dos Vedas parece extrapolar níveis mínimos de razoabilidade. $\bigcirc$ tão apregoado rompimento entre o budismo e a tradição védica, tal como cantado e 
decantado pelo discurso orientalista, serve para reforçar uma leitura positivista que confere à religiosidade ético-filosófica do budismo um caráter de evolução histórica com relação às religiosidades rituais e morais dos Vedas. Em outras palavras, e em conformidade com o modelo ocidental, o budismo estaria para a tradição védica como o cristianismo estaria para o judaísmo - um movimento rebelde do Nível 2 que objetivaria a supressão histórica do Nível 1 das religiosidades do subcontinente.

aprofundamento dos estudos das religiosidades do subcontinente indiano, em especial no que tange aos desdobramentos subsequentes do budismo na região, não deixa margem para as fantasias orientalistas. A sugestão de uma rebeldia antiritual pouco ou nada a ver com o budismo indiano e soa, ao invés, como uma proposta suicida, considerando a inarredável necessidade de uma articulação orgânica entre os dois níveis de religiosidade, onde a plena vivência do primeiro é requisito e plataforma para o desenvolvimento do segundo.

Um olhar mais cuidadoso sobre a crítica do Buda aos Vedas permite-nos concluir que o que está em causa não é a pertinência e a relevância do ritual em si, i.e., das práticas rituais e morais conducentes à fruição de paraísos efêmeros em outras vidas, mas o que lhe pareceu, à época, constituir uma tendência problemática, a saber, o ritualismo exacerbado dos brâmanes e a reificação do caminho paradisíaco - i.e., o Nível 1 do caminho espiritual -como pretensa resolução definitiva do problema do sofrimento. Com efeito, a tradição védico-bramânica alvo das críticas do Buda nos sūtras do cânon páli ${ }^{3}$ é descrita como uma prática ritual (yajña) que conduziria a alma (ātman) a uma condição definitiva de beatitude e superação do sofrimento através da união com o Brahmā, "o deus criador, ser supremo, ordenador, todo-poderoso, senhor de tudo o que existe e existirá" (BRAHMAJĀLASUTTAM, 2017).

O desenvolvimento da noção budista de anātman ("não-eu"),enquanto instrumento de rejeição das pretensas substancializações de um ritualismo védico exacerbado - viz., ātman enquanto agente interessado e brahmā enquanto deus personificado -, ocorre em paralelo ao desenvolvimento de outras vertentes críticas no interior da tradição védica. É o caso, em especial, da vertente de aprofundamento racional-reflexivo dos Upanișads, que se consolidariam como Nível 2 por excelência do processo espiritual da tradição védica, ao sustentar uma não-diferença fundamental (advaita), de caráter ontológico, entre a alma individual (ātman] e o princípio unicista do Real (Brahman). Como o demonstra a obra laboriosa de Hajime Nakamura (1990, p. 9-126) sobre as origens do Vedānta (lit. "Os Upanișads ou a "parte final dos Vedas"), a bidimensionaldade do sistema védico, entendida como um todo orgânico e integrado onde a realização do primeiro nível - os rituais e as moralidades do dharma - é requisito para a realização do segundo - a reflexão dos Upanișads sobre mokșa -, estava há muito profundamente enraizada nas tradições religiosas do subcontinente indiano. Note-se, neste partciular, que alguns dos

\footnotetext{
${ }^{3}$ Veja, por exemplo, o BrahmajālaSutta, o TevijjaSutta e o CankīSutta.
} 
principais Upanișads são seguramente anteriores ao surgimento do budismo no subcontinente indiano.

Portanto, longe de propor a supressão de níveis ou a invenção substitutiva de uma nova religião, a crítica do Buda aos eventuais excessos do ritualismo védico reitera a absoluta necessidade de se manter a estrutura bidimensional e cumpre, adequadamente, seu papel de religiosidade iniciática de Nível 2.

Do acima exposto, ressalta também a necessidade de se relativizar a ideia bastante disseminada entre estudiosos do budismo de que o Buda empreende uma condenação do sistema de castas ou da estrutura social prevalente à sua época. (GOMBRICH, 1971, p. 295]). Com efeito, o caráter iniciático do budismo indiano demanda, em sua persecução e em seu contexto específico de elegibilidade, disciplinas e estruturas pedagógicas distintas daquelas prevalentes no espaço social mais amplo das religiosidades populares de Nível 1. Não há nem poderia haver, aqui, qualquer pretensão de tornar tais disciplinas e estruturas acessíveis ao universo social mais amplo. Por outro lado, a meritocracia espiritual que condiciona, necessariamente, a definição dos critérios de elegibilidade para o empreendimento filosófico-soteriológico - viz., as qualidades éticas e intelectuais - não constituiu exclusividade do budismo: tais princípios são comuns à maioria das tradições iniciáticas de Nível 2, aí se incluindo os Upanișads. Nesse sentido, ao invés de uma crítica social ao sistema de castas, a crítica do Buda ao pretenso ritualismo brâmane constitui um apelo à necessidade imperiosa de se empreender o aprofundamento reflexivo das religiosidades, muito além de rituais e moralidades, e de se assegurar, dessa forma, o cumprimento dos critérios de elegibilidade iniciática inerentes ao Nível 2 dos processos espirituais. E mesmo assim, como o demonstra cabalmente a origem social brâmane da grande maioria dos mestres do budismo, nem sempre a aplicação prática desses critérios ficou imune a mecanismos de favorecimento relativo, em função de proveniências sociais específicas.

O desenvolvimento da tradição budista do Mahāyāna, alguns séculos após a morte do Buda histórico, como desdobramento dissidente das tradições originárias do Abhidharma, constitui um momento importantíssimo no processo de restabelecimento dos elos com as religiosidades hindus e, em particular, as matrizes védicas, que haviam sido abalados com a crítica contundente do Buda. Esse fenômeno manifesta-se em ambos os níveis do modelo bidimensional. No que tange à dimensão filosófica e iniciática (Nível 2) é notória a aproximação entre, de um lado, a tradição sútrica emergente (viz., os sūtras específicos do Mahāyāna) e suas principais escolas (o Madhyamaka e o Yogacāra), ambas consolidando uma canonicidade em língua sânscrita, e, de outro, certas correntes hermenêuticas dos Upanișads, em especial a escola do Advaita Vedānta (não-dualismo)e as tradições iniciáticas dos Tantras Śaivistas.

Das interações com os Tantras Śaivistas, cuja consolidação mais duradora foram os desdobramentos do budismo vajrāyāna no Tibet (SANDERSON 2009), surgemvariantes disciplinares de grande repercussão, como é o caso da "laicidade 
iniciática" que contempla a utilização, sempre condicionada ao preenchimento dos pré-requisitos de elegibilidade, das práticas cotidianas como trampolim para a realização do nirvāna. Caso emblemático desse processo é a centralidade narrativa do bodhisattva leigo Vimalakīrti no sūtra homônimo denominado Vimakīrtinirdeśa Sūtra. Por outro lado, o desdobramento de conceitos-chaves do budismo - e.g., a "co-originação dependente"(pratītya-samutpāda) e a "vacuidade" (sūnyatā) - em versões eminentemente positivas como é o caso da noção de Absoluto ou "Natureza Búdica"(Tathāgatagarbha) aproximam grandemente o empreendimento budista da tradição dos Upanișads e seu Absoluto ontológico Brahman. (MURTI 2003) Testemunho disso é uma passagem extraordinária do Lańkāvatāra Sūtrana qual Mahāmati, discípulo do Buda, pergunta ao mestre se, de fato, o Tathāgatagarbha do budismo e o Brahman dos Upanișadsnão seria uma mesma realidade ou, em outras palavras, se ambos não cumpririam funcionalidades soteriológicas idênticas.( LAN̈KĀ VATĀRA SÜTRA 2017, II.137)

Mas talvez o aspecto mais importante e menos estudado desse processo sejam as reconexões orgânicas com dimensões de Nível 1 das religiosidades védicas, purânicas e tântricas, em especial as tradições do Śaivismo popular. É nesse cadinho de um hinduísmo popular difuso que se constitui o que poderíamos designar por um "budismo popular ou laico", i.e., um budismo de ritualidades e moralidades que projeta existências futuras em paraíso efêmeros e que não deve, de forma alguma, ser confundido com o que acima designamos por "laicidade iniciática". É também nesse contexto popular que emerge uma das muitas funcionalidades do bodhisattva, ideal supremo da condição de conhecimento e compaixão plenas do Mahāyāna. Se no contexto iniciático sua função precípua é a guiar os neófitos nos caminhosda reflexão que conduzem ao nirvāṇa, no contexto das religiosidades populares, o bodhisattva assume o papel de divindade devocional cuja missão é restaurar o equilíbrio cósmico e a moralidade decaída, e propiciar aos devotos uma condição paradisíaca pós-mortem. Percebe-se, neste particular, uma similaridade funcional muito clara entre os bodhisattvas budistas e os avatares hindus de Viṣnu e Śiva, reflexo de uma intensa interação entre ambos nos contextos mais amplos das religiosidades populares.

Em síntese, o processo de reconexão orgânica do budismo e seu viés eminentemente iniciático com as religiosidades hindus (védicas/purânicas/tântricas) do subcontinente indiano, tanto em suas dimensões populares quanto naquelas de aprofundamento reflexivo, caracteriza, peculiarmente, a tradição do Mahāyāna e fornece os elementos epistemológicos fundamentais para a compreensão dos processos análogos que acompanharam a assimilação da palavra do Buda em territórios e civilizações distintos como é o caso do Tibet, da China e do Japão. $\bigcirc$ processo de revestimento e adequação gradual dos ensinamentos do Buda aos contextos locaise suas religiosidades plurais, e em especial seus níveis introdutórios e populares, gestou ao longo de séculos de maturação e diálogo, o que designamos hoje por "religiões budistas". Tratam-se, portanto, de religiões cuja 
compreensibilidade está intimamente condicionada à compreensibilidade prévia das tradições locais pré-budistas como é o caso do taoísmo, do confucionismo e do xintoísmo, entre outras.

\section{IV - Conclusão}

Pretendemos, com os parágrafos acima, evidenciar a inserção civilizacional eminentemente hinduísta da tradição do budismo, cujo contexto originário possui um caráter eminentemente iniciático (Nível 2). Caem por terra, com isso, alguns dos fetiches orientalistas que estão na raiz da percepção generalizada, que prevalece até os dias de hoje, de um fosso incontornável que separaria o budismo do hinduísmo. E o maior desses fetiches é, sem dúvida, a presunção enraizada de que a noção de anātman ["não-eu"] representaria, necessariamente, o oposto exato de todas as postulações hinduístas de um ātman ("consciência pura"). É, finalmente, na tradição budista do Mahāyāna e, mais especificamente, nos desenvolvimentos notáveis aí transcorridos com relação à noção upāya que se esclarece, em definitivo, o sentido contextual da formulação crítica da ideia de anātman ["não-eu"): a noção de anātman é, fundamentalmente, um upāya, i.e., um instrumento estratégico, entre tantos outros utilizados pelo Buda, visando à eliminação de um erro específico sobre a natureza das coisas. Crítico dos excessos da ritualística védica, a postulação do anātman pelo Buda visa exclusivamente à refutação da ideia reificada de salvação como desfrute de uma condição paradisíaca em outro mundo.

Na contracorrente dos princípios de operacionalidade do upāya, parte da intelectualidade ocidental tende a transformar o anātman numa declaração de absoluta não-existência de qualquer fundamento, numa postura que beira o niilismo. Ao invés, as palavras do Buda não reivindicam para si qualquer status metafísico: elas situam-se igualmente equidistantes tanto das declarações absolutas de existência (śāśvatavāda) quanto das declarações absolutas de não-existência (ucchedavāda). A rejeição a ambas as polaridades discursivas visa, finalmente, mover os neófitos de buscar qualquer forma de objetificação do fundamento, pois reside precisamente nessa disposição à objetificação do inobjetificável a causa do sofrimento e da ignorância humanas. Em outras palavras, tal como a tradição védica dos Upanișads, e tal como a tradição tântrica do Śaivismo, o budismo comporta sim uma ontologia não-dual, que rejeita todas as metafísicas da objetificação.

Num dos sūtras mais notáveis do cânon páli, o Buda não deixa dúvidas com relação ao sentido puramente instrumental e pedagógico de suas palavras, ao proclamar que nem o ātman nem o anātman representam a ontologia budista:

"Venerável Gautama, pergunta Vaccagotta, existe um ātman?". O Buda permanece em silêncio. "Venerável Gautama, pergunta Vaccagotta, existe um anātman?". O Buda permanece em silêncio. [ĀNANDA [ATTHATTA] SUTTA, 2017) 


\section{REFERÊNCIAS BIBLIOGRÁFICAS}

ĀNANDA(ATTHATTA)SUTTA. (original páli). In Sutta Pițaka. http:/ / www.accesstoinsight.org/ tipitaka/sltp/SN_IV_utf8.html\#pts.400.Acesso: Agosto, 2017.

BRAHMAJĀLASUTTAM (original páli). In Sutta Pițaka. http:/ / www.accesstoinsight.org/tipitaka/sltp/DN_I_utf8.htm. Acesso: Agosto, 2017.

GOMBRICH, Richard. Precept and Practice: Traditional Buddhism in the Rural Highlands of Ceylon. Oxford: Clarendon Press, 1971.

LANंKĀ VATĀRA SÜTRA. (original sânscrito) http:/ / www.dsbcproject.org/node/ 4102. Acesso: Agosto, 2017.

MURTI, T. R. V.Central Philosophy of Buddhism: A Study of Madhyamika System. New Delhi: Munshiram Manoharlal, 2003.

NAKAMURA, Hajime. History of Early Vedanta Philosophy. Delhi: Motilal Banarsidass, 1990.

SANDERSON, Alexis. The Śaiva Age: The Rise and Dominance of Śaivism During the Early Medieval Period. In EINOO, Shingo (org.). Genesis and Development of Tantrism. Tokyo: Institute of Oriental Culture, University of Tokyo, 2009, p. 17349.

BRYANT, Edwin. The Quest for the Origins of Vedic Culture. New York: Oxford University Press, 2003. 